\title{
La posición de Jovellanos en el debate para la admisión de mujeres en la Real Sociedad Económica Matritense de Amigos del País
}

\author{
Olegario Negrín Fajardo
}

Departamento de Historia de la Educación y Educación Comparada (UNED)

CES.XVIII, núm. 21 (2011), págs. 149-171. 
Resumen: El debate de la Real Sociedad Económica Matritense de Amigos del País de 1775 y 1786, acerca de la admisión de mujeres en sus actividades, estaba relacionado con la consolidación de unos modelos de masculinidad y feminidad y el dominio de las funciones de lo privado y lo público. En su intervención, Jovellanos se inclinó por la posición oficial en que la mujer debía desempeñar las funciones de administradora del hogar y educadora de sus descendientes en el ámbito doméstico, mientras que las funciones públicas quedaban en manos de los hombres. Apoyaba que las mujeres colaboraran con los hombres en facetas que consideraba propias del sexo femenino, como la beneficencia pública y la educación de las niñas y mujeres populares, dentro del utilitarismo ilustrado de poner la educación al servicio del desarrollo económico.

Palabras clave: Real Sociedad Económica Matritense. Jovellanos. Admisión de mujeres, feminismo e Ilustración española. Educación y desarrollo económico. 


\section{Introducción}

La primera vez que tuvimos noticia del debate ilustrado acerca de la admisión de mujeres en la Real Sociedad Económica de Amigos del País de Madrid, o Matritense, fue mientras realizábamos nuestra tesis doctoral centrada en la dimensión pedagógica de la mencionada Real Sociedad madrileña ${ }^{1}$. Con posterioridad, volvimos a tratar el tema en nuestro libro Ilustración y educación. La Sociedad Económica Matritense ${ }^{2}$ y en una comunicación presentada en el Eighth International Congress on the Enlightenment ${ }^{3}$, celebrado en Bristol en julio de 1991. Antes se había referido al citado debate, de forma amplia y detallada, Lucienne Domergue en su libro Jovellanos à la Societé Économique des Amis du Pays de Madrid (1778-1795)4.

Después de nuestras publicaciones, otros autores han vuelto sobre el asunto con mayor o menor extensión, ocupándose de analizar el pensamiento de alguno de los participantes dieciochescos del debate la Matritense. Entre otros, hay que destacar el trabajo de Pilar Pérez Cantó y Esperanza Mo Romero, «Las mujeres en los espacios ilustrados» (Signos históricos, núm. 13 [enero-junio 2005], págs. 43-69); de las mismas autoras, «Ilustración, ciudadanía y género» (en P. Pérez

$1 \quad$ El título completo de la tesis presentada en la Universidad Complutense de Madrid en 1978 fue La Real Sociedad Económica Matritense de los Amigos del País. Su obra pedagógica, publicada en buena parte en el libro La educación popular en España en la segunda mitad del siglo XVIII, Madrid, UNED, 1987; se pueden consultar especialmente las págs. 121-130 acerca del debate de admisión de mujeres en la Sociedad. Otros contenidos de la tesis aparecieron como artículos de revistas de la especialidad y en comunicaciones a congresos nacionales e internacionales; algunos de ellos forman parte de nuestro libro Veinticinco ensayos de historia de la educación moderna y contemporánea, Madrid, unED, 2005.

2 Madrid, Editora Nacional, 1984.

3 «El largo debate sobre la admisión de mujeres en la Sociedad Económica de Amigos del País de Madrid.» No obstante, el citado congreso de la International Standing Conference for the History of Education, celebrado del 21 al 27 de julio de 1991, no publicó ese año sus actas, sino un resumen de las mismas, así que el contenido de nuestra comunicación había permanecido inédito hasta el momento.

4 Esta obra, basada en su tesis del doctorado de tercer ciclo, fue publicada en Toulouse, por FranceIbérie Recherche de la Universidad de Toulouse-le Mirail, en 1971. Es un trabajo muy apreciable al que hay que acudir si se quiere conocer con detalle la relación de Jovellanos con la Matritense. En el capítulo nueve, de la cuarta parte del libro, se estudia el debate acerca de la admisión de mujeres en la Real Sociedad y la actitud mostrada por una serie de socios, entre ellos Jovellanos. No obstante, es necesario revisar sus principales argumentos a la luz de la historiografía actual y lo nuevos enfoques de género, actividad que en parte realizamos en esta aportación. 
Cantó [ed.]: También somos ciudadanas, Madrid, Instituto Universitario de la Mujer, 2000, págs. 43-1411), y de Gloria A. Franco Rubio, «La contribución literaria de Moratín y otros hombres de letras al modelo de mujer doméstica» (Cuadernos de Historia Moderna, anejos, VI [2007], págs. 221-254). Las tres contribuciones se apoyan en nuestro análisis y recopilación del debate en el libro de Editora Nacional que hemos citado. Pero estamos ante una cuestión de género y sobre este aspecto en la perspectiva de la Ilustración se ha trabajado bastante en los últimos años ${ }^{5}$.

5 Entre las publicaciones recientes destacamos las siguientes: Mujeres y hombres en la formación del pensamiento occidental. Actas de las VII Jornadas de Investigación Interdisciplinar, Madrid, Ediciones de la Universidad Autónoma, 1989; M. Bolufer Peruga, Mujeres e Ilustración. La construcción de la feminidad en la España del siglo XVIII, Valencia, Alfons el Magnànim, 1998; «Mujeres y hombres en los espacios de reformismo ilustrado: debates y estrategias», Debats, 2003; «Lo íntimo, lo doméstico y lo público: representaciones sociales y estilos de vida en la España ilustrada», Studia Historica. Historia Moderna, 19 (1998), págs. 85-116, y «Representaciones y prácticas de vida: las mujeres en España a finales del siglo XVIII», Cuadernos de Ilustración y Romanticismo, 11 (2003); M. ${ }^{a}$ V. López-Cordón CorTEzo, «Los orígenes de la polémica feminista», Torre de los Lujanes, 48 (octubre 2002), y Condición femenina y razón ilustrada: Josefa Amar y Borbón, Zaragoza, Prensas Universitarias de Zaragoza, 2005; G. Franco Rubio, «La reapertura de la querella de las mujeres a comienzos del siglo XvIII: la polémica defensa de las mujeres de Feijoo», en VII Seminario Permanente de Fuentes Literarias para la Historia de las Mujeres, Madrid, 2008; M. ORTEga LóPEZ (dir.), Las mujeres de Madrid como agentes de cambio, Madrid, Universidad Autónoma de Madrid, 1995; J. Cruz, «De cortejadas a ángeles del hogar. Algunas reflexiones sobre la posición de la mujer en la élite madrileña. 1750-1850», en A. SAINT-SAËNS, Historia silenciada de la mujer. La mujer española desde la época medieval hasta la contemporánea, Madrid, Editorial Complutense, 1996, págs. 135-160; V. vON DER HEYDENRynsch, Los salones europeos. Las cimas de una cultura femenina desaparecida, Barcelona, Península, 1998; Condorcet, De Gouges, De Lambert y otros, La Ilustración olvidada. La polémica de los sexos en el siglo XVIII, Barcelona, Anthropos, 1993; M. Díaz-Diocaretz e I. M. Zavala, Breve historia feminista de la literatura española (en lengua castellana), Barcelona, Anthropos, 1993-2000; I. Morant, «Hombres y mujeres en el espacio público», en M. C. Roмeо Mатео y otros, Orígenes del liberalismo: universidad, política, economía, Actas Salmanticensia, Estudios Históricos y Geográficos, 124, Salamanca, Universidad de Salamanca, 2003, págs. 117-140; T. A. Sмгтн, The Emerging Female Citizen Gender and Enlightenment in Spain, Berkeley, University of California Press, 2006. Otras obras que no pueden dejar de citarse para el periodo final de la Edad Moderna y comienzos de la contemporaneidad son: M. RoIG, A través de la prensa. La mujer en la historia, Madrid, Ministerio de Asuntos Sociales, 1989; C. Molina Petrt, Dialéctica feminista de la Ilustración, Barcelona, Anthropos, 1994; M. NASH, Mujeres en el mundo. Historia, retos y movimientos, 3. ${ }^{\text {a }}$ ed., Madrid, Alianza, 2007; «Identidad de género, discurso de la domesticidad y la definición del trabajo de las mujeres en la España del siglo XIX», en G. Duby, Historia de las mujeres en Occidente, vol. IV, Madrid, Taurus, 1993; J. S. Amelang y M. Nash, Historia y género. Las mujeres en la España moderna y contemporánea, Valencia, Alfons el Magnànim, 1990; I. Morant, Historia de las mujeres en España y América latina, Madrid, Cátedra,

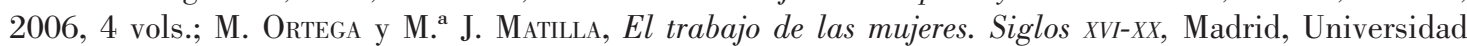
Autónoma, 1996; Las mujeres en el Antiguo Régimen. Imagen y realidad, Barcelona, Icaria, 1998; M. ${ }^{a}$ I. VAL VALDIVIESO Y OTRos, La historia de las mujeres: una revisión historiográfica, Valladolid, Universidad de Valladolid, 2004; C. Amorós, Historia de la teoría feminista, Madrid, Instituto de Investigaciones Feministas - uGM - Dirección General de la Mujer, 1994; C. Amorós y A. de Miguel, Teoría feminista: de la Ilustración a la globalización. De la Ilustración al segundo sexo, Madrid, Minerva, 2005; O. Blanco Corujo, «La ilustración deficiente. Aproximación a la polémica feminista en la España del siglo XVIII», en C. Amorós y A. de Miguel, Teoría feminista: de la Ilustración a la globalización. De la Ilustración al segundo sexo, Madrid: Minerva, 2005, págs. 145-175. 
Nos parece muy acertada la posición de Pérez Cantó y Mo Romero cuando afirman:

Uno de los logros más visibles de la Ilustración fue la generación de nuevos espacios de sociabilidad, circunstancia que nació asociada a las dificultades encontradas para promover la innovación de los conocimientos científicos o generar opinión a partir de las instituciones tradicionales. La resistencia que desde las cátedras universitarias y las instituciones eclesiásticas se planteó a la penetración de cualquier novedad que no estuviera sancionada por la tradición o por autoridades incontestadas forzó a los ilustrados, con apoyo gubernamental o sin él, a idear nuevas formas de relacionarse y generar asociaciones, academias, tertulias y un sinnúmero de nuevos instrumentos de difusión de las luces que propugnaban. Lo que aquí nos interesa señalar es el modo en que las mujeres aprovecharon esos nuevos espacios para hacerse un lugar en la nueva sociedad, eligiendo como ejemplo a la Corte madrileña ${ }^{6}$.

El detonante más inmediato del interés por el tema de la mujer en la segunda mitad del siglo XVIII español fue, con toda probabilidad, el libro Discurso sobre el fomento de la industria popular ${ }^{7}$, de Campomanes, entonces fiscal del Consejo de Castilla, que defendió la necesidad de utilizar el trabajo productivo femenino al servicio de su política económica. Con anterioridad, Feijoo había planteado en la primera mitad del siglo ilustrado la igualdad intelectual entre mujeres y hombres en su discurso sobre la Defensa de la mujer ${ }^{8}$, que dejaba abierta la posibilidad y necesidad de su educación:

6 La cita transcrita está recogida del resumen de su artículo «Las mujeres en los espacios ilustrados», citado anteriormente, y revela con precisión uno de los indudables méritos de la Ilustración española, que nos sirve de referencia para introducir las dimensiones del debate por la admisión de mujeres en la Matritense. Como veremos, la elaboración de las memorias a favor, la mayoría, o en contra, únicamente la de Francisco de Cabarrús, no fue fruto de la casualidad, sino que se convirtió en la respuesta de la Sociedad Económica madrileña a un problema que estaba en la prensa, en las tertulias, en el pueblo y en el Gobierno que tenía que ver con la confrontación entre diversos modelos de mujer que se proponían en el último tercio de siglo XVIII español. En el artículo mencionado, sus autoras se refieren a las nuevas formas de sociabilidad que facilitaron la participación femenina en pie de igualdad con la masculina, especialmente en los salones, academias, sociedades y el teatro.

7 Vid. Campomanes, Discurso sobre el fomento de la industria popular, Madrid, Sancha, 1774; Discurso sobre la educación popular de los artesanos y su fomento, Madrid, Sancha, 1775; Apéndice al Discurso de educación popular, Madrid, Sancha, 1775-1777, 5 tomos.

8 Cfr. B. J. Feijoo, Teatro crítico, Madrid, Icaria, 1997 (la edición original fue editada en la imprenta de Benito Cosculluela, 1784-1785). El discurso XVI está dedicado a la defensa de la mujer. La mayoría de los análisis acerca del tema de la situación de las mujeres en el siglo XvIII hacen alusión al significado que tuvo el citado discurso. Como ejemplo, se puede mencionar el artículo citado «La ilustración deficiente. Aproximación a la polémica feminista en la España del siglo XviII», de O. Blanco Corujo. 
En grave empeño me pongo. No es ya sólo el vulgo ignorante con quien entro en la contienda: defender a todas las mujeres viene a ser lo mismo que ofender a todos los hombres: pues raro hay que no se interese en la precedencia de su sexo con desestimación del otro. A tanto se ha extendido la opinión común en vilipendio de las mujeres que apenas admiten en ella cosa buena. En lo moral las llena de defectos, y en lo físico de imperfecciones. Pero, donde más fuerza hace es en la limitación de los entendimientos. Por esta razón, después de defenderla con alguna brevedad sobre estos capítulos discurriré más largamente sobre su aptitud para todo género de Ciencias y conocimientos sublimes?

\section{Esta posibilidad de educación para las mujeres supuso, para Pérez Cantó y Mo Romero,}

[...] un punto de no retorno y algunas de ellas avanzaron por ese camino, aunque habría que añadir que la educación reivindicada por los ilustrados parta el sexo femenino no era un medio para lograr mujeres sabias capaces de ocupar un lugar en la nueva sociedad, pues ésta no fue concebida como un instrumento para educar a ciudadanas útiles a la patria —lenguaje tan querido por los proyectistas de la segunda mitad del siglo— se trataba, más bien, de perfilar un modelo de mujer-esposa-madre instruida, eficaz, sabia consejera de su esposo, buena administradora de la hacienda familiar, defensora del honor de la familia y educadora de ciudadanos ${ }^{10}$.

Otro aspecto que consideramos interesante resaltar en esta introducción es la implantación del modelo de educación doméstica con fuerte arraigo en nuestras sociedades en el que a la mujer le tocaba desempeñar las funciones clásicas de «buena hija, buena esposa y buena madre», encargada del hogar, «de la sociedad doméstica», sin ninguna dimensión pública oficialmente aceptable. De hecho, con la Ilustración se afianzará la dimensión pragmática de la educación

9 Así empieza el discurso XVI citado, avanzando los contenidos del mismo, y centrándose en la igualdad de género ante la educación, la ciencia y la cultura. No fueron pocos los opositores que tuvo el benedictino y que dieron a conocer sus puntos de vista opuestos radicalmente en las materias de género. No hay que olvidar que la prensa, uno de los cauces ilustrados por excelencia, se muestra innovadora en política, medicina, ciencias experimentales, pero no así en el tema de la igualdad entre los sexos, en el que defiende la invención del «ama de casa» de la ideología burguesa. Cfr. P. Guinard, La presse espagnole de 1737 à 1791. Formation et signification d'un genre, París, Centre de Recherches Hispaniques, 1973.

10 Cfr. «Las mujeres en los espacios ilustrados», pp. 45-46. Las autoras del artículo citado siguen afirmando que no se trataba de formar bachilleras «que ostentasen en público su talento y reivindicasen espacios y derechos que no le correspondían», sino de que las mujeres aprovecharan las brechas que la Ilustración les proporcionó en el modelo diseñado para ellas, para que se hicieran presentes en la sociedad de su época, como ocurrió con las tertulias y salones, la prensa y las asociaciones como la Matritense. 
al servicio de la economía y el desarrollo nacional y, desde esa perspectiva, se van a dar pasos firmes hacia la postulación de una formación femenina basada precisamente en ese criterio.

Para Gloria A. Franco, el proceso de construcción cultural y político de los paradigmas genéricos de las clases medias en el siglo xvIII, con el triunfo del modelo de la mujer doméstica, «

[...] cortó de raíz una trayectoria de visibilidad social y de autonomía personal en la vida de las mujeres que se habría iniciado en el Medievo con el fenómeno del «amor cortés»; habría proseguido después mediante su participación en los cenáculos literarios de la República de las Letras durante el Renacimiento, y se había mantenido más adelante con la aparición del movimiento de «las preciosas» en Francia durante el siglo XVII para continuar posteriormente, durante la centuria ilustrada, con la eclosión de los salones, herederos del preciosismo ${ }^{11}$.

Los diferentes géneros literarios contribuirían «no sólo a la creación de los paradigmas genéricos, de la feminidad y la masculinidad, sino también a la difusión de dicho modelo al haber convertido la literatura en uno de los instrumentos propagandísticos de la ideología burguesa en esa coyuntura crucial de finales del Antiguo Régimen». Para esta autora, tales paradigmas se definieron por unos espacios, unas funciones y unos valores a desarrollar en la nueva sociedad, en la que a la mujer se le excluyó del espacio público y se le confinó en el ámbito privado de lo doméstico ${ }^{12}$.

Como se puede deducir de lo que venimos afirmando y de las citas y fuentes bibliográficas señaladas, el debate de la Matritense no fue una mera discusión más o menos ociosa entre socios masculinos sin mejor tema de que ocuparse. La cuestión que se debatía en la Matritense era seria y pertinente porque se trataba de una batalla más por la consolidación de unos modelos de masculinidad y feminidad $o$, si se quiere, de discusión de las diversas tesis que se enfrentaban en tal contienda por el dominio, y reparto en su caso, de los roles de lo privado y lo público.

Como marco de referencia de este artículo, además de la dialéctica ya avanzada entre los géneros y sus funciones, hay que considerar a las Sociedades Económicas de Amigos del País en el último tercio de la centuria ilustrada como

11 G. A. Franco Rubio, «La contribución literaria de Moratín y otros hombres de letras al modelo de mujer doméstica», Cuadernos de Historia Moderna, anejos, VI (2007), págs. 221-254 (pág. 224).

12 Ibidem, págs. 221-254. En el trabajo citado se estudia el proceso de construcción de los arquetipos de género a través de diversos autores, para demostrar en qué medida la literatura se utilizó como agente de confirmación de modelos de masculinidad y feminidad. 
«espacios públicos formales», creados por el poder ilustrado como cauces de reforma y, con frecuencia, en lugar para el debate para la elaboración de alternativas prácticas que dieran respuestas a las situaciones problemáticas existentes.

En la segunda mitad del siglo XVIII, más en concreto a partir de 1775, fecha de creación de la Sociedad Económica de Amigos del País de Madrid, referencia siempre obligada en consonancia con la estructura política centralista de la época ${ }^{13}$, empezaron a desarrollarse en amplio número por toda España unos organismos no oficiales denominados Sociedades Económicas de Amigos del País ${ }^{14}$, que tenían la misión de extender los conocimientos y habilidades precisos para el fomento de la agricultura, la industria, los oficios, el comercio y las ciencias, mediante la apropiada enseñanza profesional. Los antecedentes próximos de las Sociedades fueron las reuniones y tertulias de carácter literario, científico y artístico en asociaciones informales; también está probada la influencia en las Económicas españolas de sociedades y academias extranjeras, como la Sociedad de Ciencias Útiles de Zurich y las sociedades de Dublín, París, Berna y Bretaña.

Las funciones y características más significativas de las Económicas fueron planteadas por Campomanes en sus conocidos Discursos: hacer el diagnóstico permanente de la realidad socio-económica de cada provincia, estudiar detalladamente las producciones y el número de vagos y mendigos, hacer publicaciones y crear premios e incentivos diversos, para el fomento de nuevas experiencias y para aumentar la cantidad y la calidad de la producción, facilitar que todos los grupos sociales colaboren estrechamente en el desarrollo del país. Fueron Sociedades uniformes en sus estatutos, reglamentos, trabajos y publicaciones. Los socios se agrupaban en las clases de agricultura, industria y artes y oficios,

13 No deja de ser llamativo que con frecuencia se olvide que la primera Real Sociedad Económica fue la Vascongada, creada en el País Vasco; la Real Sociedad Vascongada de Amigos del País, también conocida como La Bascongada, surgió de la mano de los Caballeritos de Azcoitia, Xavier María de Munibe e Idiáquez, conde de Peñaflorida, junto a José María de Eguía, marqués de Narros, y Manuel Ignacio Altuna. En 1763 presentaron el plan de creación en Vergara, siendo aprobado en 1765; sus actividades en diversos ámbitos de la economía, la cultura y la educación fueron pioneras y referentes para el resto de las Económicas españolas.

14 Sobre las Sociedades Económicas de Amigos del País existe una amplia bibliografía en castellano. Entre otras, son de consulta imprescindible las siguiente obras: F. Aguilar y otros, Las Sociedades Económicas de los Amigos del País. Guía para el investigador, San Sebastián, Patronato J. M. Quadrado, 1974. E. NovoA, Las Sociedades Económicas de los Amigos del País. Su influencia en la emancipación colonial americana, Madrid: Prensa Española, 1955; E. Ruiz y González de Linares, Las Sociedades Económicas de los Amigos del País, Burgos, CSIC, 1972; R. SHAFEr, The Economic Societies in the Spanish World (1763-1821), Syracuse, University Press, 1958; Las Reales Sociedades Económicas de Amigos del País y su obra, San Sebastián, Patronato J. M. Quadrado, 1972. Recientemente, el profesor Luis Miguel Enciso Recio ha publicado una obra de síntesis que recoge las aportaciones del conjunto de las Sociedades Económicas españolas: Las Sociedades Económicas en el Siglo de las Luces, Madrid, Real Academia de la Historia, 2010. Además, durante todos estos años se han publicado estudios acerca de la mayor parte de las Sociedades Económicas provinciales ilustradas. 
que se ocupaban de analizar la situación en sus respectivas áreas y plantear mejoras y alternativas. Una de sus labores fundamentales fue el fomento de la enseñanza ${ }^{15}$.

Teniendo en cuenta el contexto histórico y metodológico expuesto, el verdadero centro de interés de esta aportación es el citado debate abierto en la Sociedad Económica Matritense en torno a si era adecuado y útil que las mujeres participasen en las actividades de la misma ${ }^{16}$. A través del breve análisis que hacemos de las diversas intervenciones de los socios que se produjeron, se podrán observar las diferentes perspectivas de análisis que existían en aquellos momentos y podremos destacar las semejanzas y diferencias de la posición de Gaspar Melchor de Jovellanos con el resto de intervinientes. La documentación existente en el archivo de la Matritense revela que, más allá de lo llamativo que pudiera resultar el largo debate, lo verdaderamente importante era que se estaban discutiendo temas fundamentales, relacionados con el progreso socioeconómico, la modernización del país y, en definitiva, el cambio y la adecuación de mentalidades a las corrientes europeas ilustradas.

\section{La admisión de socias en la Matritense: un largo debate}

Aunque nunca dejó de hablarse del todo del tema de la admisión de las mujeres en la Sociedad Económica Matritense, y en otras Sociedades Económicas, en el caso de la Económica madrileña el debate tuvo dos momentos intensos. El primero, al poco tiempo de establecerse la entidad, especialmente por una de las dimensiones fundamentales que había de desarrollar, que tenía que ver con la educación popular y con la beneficencia pública, y que pronto comprenden los socios las dificultades que encerraba; luego se produce un largo silencio oficial, aunque el tema sigue estando larvado, y surge el segundo momento en torno a 1786. Hay que tener en cuenta la importancia de la aspiración porque, como dijo Sempere y Guarinos, «hasta el reinado de Carlos III no se ha visto en España ninguna asociación de mujeres autorizadas por el Soberano, a excepción de los monasterios, congregaciones, cofradías y otras juntas dirigidas únicamente a ciertos ejercicios de piedad y devoción» ${ }^{17}$.

15 Vid. R. Carande, Siete estudios de historia de España, Barcelona, Ariel, 1969, pág. 170.

16 Los documentos del debate y un estudio amplio sobre el mismo pueden encontrarse en O. NEGRín, Ilustración y educación. La Sociedad Económica Matritense, Madrid, Editora Nacional, 1984, y La educación popular en la España de la segunda mitad del siglo XVIII, Madrid, UNED, 1987.

17 J. Sempere y Guarinos, Ensayo de una biblioteca española de los mejores escritores del reinado de Carlos III, Madrid, Imprenta Real, 1789, t. V, pág. 213. 
Fue José Marín ${ }^{18}$ el primer socio que presentó una memoria en la que planteaba la necesidad de que se permitiera la entrada de las mujeres (madres, esposas, hermanas e hijas) de los socios de la Matritense ${ }^{19}$. Marín, apoyándose en Campomanes y de la Quadra ${ }^{20}$, proponía que se admitiera a dichas mujeres en calidad de asociadas, sin obligación de asistir a las juntas. Ello traería consigo una mayor emulación en los hombres, la industria popular se extendería por todas partes y reinaría el cuidado, la limpieza y el orden. Propone que formen clase separada con la denominación que se considerara más adecuada, aunque él adelanta que no le gusta el nombre de «socias», "poco usado en nuestro castellano, y menos las de "académicas" llamándose Sociedad y no academia nuestra asociación, las llamaré "asociadas"» .

Marín adopta una postura propia de la época y se pregunta:

¿Qué ventajas no se seguirían a la noble emulación con que nuestras damas procurarían acreditar sus talentos y aprovechar sus luces?. ¿Y la discreción y estudio con que los hombres competirían por merecer la preferencia en su estimación?. Y por estos medios, ¿qué acogida, aplicación y gusto no encontrarían la Industria, la Agricultura y las Artes en el corazón de los españoles?21

Pone una serie de ejemplos españoles y extranjeros de instituciones en las que participaban las mujeres y adelanta actividades en las que podrían cola-

18 Era caballero de la Orden de Santiago y ayuda de Cámara de su majestad y participaba con frecuencia en las tareas de la Sociedad. Cfr. Tато y Амaт: Un triunfo de la Económica Matritense, Madrid, Imprenta Izaguirre, 1934, pág. 24. El título completo de su memoria es «Memoria del Señor D. Manuel José Marín sobre la utilidad que puede resultar al establecimiento de la Sociedad la admisión de las mujeres, bajo el título de asociadas». Esta memoria fue leída en la Junta de la Sociedad de 28 de octubre de 1775. Más datos en V. Palacio Atard, Los españoles de la Ilustración, Madrid: Guadarrama, 1964, pág. 245; J. SARrailh, La España ilustrada de la segunda mitad del siglo XVIII, México, FCE, 1957, pág. 515; A. Domínguez Ortiz, Sociedad y Estado en el siglo XVIII español, Barcelona, Ariel, 1976, págs. 279 y ss.

19 Archivo de la Real Sociedad Económica Matritense (en adelante, ARSEM), leg. 3, doc. 36. Hay que tener en cuenta que se trataba de discutir la entrada de damas de la burguesía y nobleza madrileña y, en ningún caso, de mujeres del pueblo. Era claramente un planteamiento clasista en el que se esperaba que las mujeres de clases altas dieran ejemplo de laboriosidad y valores sociales y morales a las mujeres populares, a las que, desde una perspectiva benéfica y caritativa, procurarían ayudar con sus enseñanzas y ofreciéndoles trabajo productivo.

20 Antonio de la Quadra, el primer director de la Sociedad, pronunció un interesante discurso sobre el papel de las escuelas patrióticas en la instrucción femenina, el 14 de octubre de 1775. Vid. Memorias de la Sociedad Económica Matritense, t. III, págs. 1-14, y Libro de Acuerdos de la Sociedad, años 1775 y 1776 . También Campomanes se había referido a la educación femenina en su Discurso sobre el fomento de la Industria Popular, pág. 47. En ambos casos se resaltaba la importancia de la incorporación de la mujer a las actividades productivas y a su necesaria cooperación con la Sociedad Económica Matritense, eso sí, específicamente en los ámbitos «mujeriles».

21 Ibidem, pág. 135. 
borar más directamente en los ámbitos de acción de la Sociedad Económica, y afirma: «No es posible enumerar todos los aprovechamientos que es capaz de producir el sexo femenino, si a ejemplo de las señoras asociadas se difunde en todas las mujeres, como parece verosímil, una noble afición y gusto a promover la Agricultura y las artes. ¿Qué ahorros no logrará su economía casera? ¿Qué industria no empleará su sagacidad en beneficio propio y del público? ¿Y qué medios no descubrirá su ingeniosa aplicación para acreditarse de útil a la patria ${ }^{22}$. Para justificar sus esperanzas menciona también la calidad de la producción artesanal en distintas provincias españolas.

Debió de despertar bastantes críticas la memoria de Marín, porque, poco después, el propio Campomanes se creyó obligado a intervenir defendiendo la baza de la admisión de las mujeres como socias, hecho que juzgaba «no sólo justo, sino conveniente y necesario ${ }^{23}$. Coincidente con los planteamientos de Marín, insiste en sus conocidas tesis de una educación común para los dos sexos y en la equiparación a todos los efectos de los socios y las socias en el seno de la Sociedad, incluyendo la de colaborar económicamente para su sostenimiento.

Se extiende Campomanes en su memoria en una serie de consideraciones educativas recordando la importancia que las mujeres tenían en la formación de sus hijas y la función que podrían tener las Escuelas Patrióticas contando con la colaboración de las amas de casa. Como no podría ser de otra manera, el entonces fiscal del Consejo de Castilla recuerda la importancia de la educación artesanal, bien en las casas, bien en las escuelas creadas con tal fin, para el desarrollo económico y prosperidad nacional. De esa manera, las mujeres liberarían a los hombres de tareas textiles para que pudieran dedicarse a las actividades más rudas y que exigieran un mayor poder físico ${ }^{24}$.

Entiende que las futuras socias tendrán también que efectuar su aportación económica y sobre todo divulgar en su entorno familiar y social las memorias de la Sociedad Económica, para que se propagase así la prosperidad pública. Campomanes expone con claridad su tesis principal, que no es otra que fomentar la participación de todas las mujeres en actividades productivas, entendiendo que las socias de la Matritense podrían ser las auspiciadoras de tales labores.

En abril de 1776 terciaba en el debate Luis de Imbille ${ }^{25}$, que, insistiendo en los argumentos expuestos por los otros autores citados, centra su aportación

$22 \quad$ Ibidem, pág. 141.

23 Vid. ARSEM, leg. 3, doc. 27.

24 Resaltamos la importancia que tuvo Campomanes como teórico de la educación popular en nuestro trabajo «La reforma ilustrada de la educación popular al servicio del desarrollo económico en Campomanes», en D. Mateos Dorado (ed.), Campomanes, doscientos años después, Oviedo, Instituto Feijoo de Estudios del Siglo XVIII, 2003, págs. 529-546.

25 Vid. ARSEM, leg. 3, doc. 29. 
en si las asociadas debían o no cotizar. Para superar el problema proponía una solución intermedia, estableciendo varias clases de asociadas: unas darían una aportación económica y otras colaborarían con sus trabajos domésticos y artesanales. En su memoria, Imbille reconocía que, aunque se habían «presentado dificultades sobre el modo de efectuar la entrada, no parecen suficientes para que la Sociedad se prive de tan poderoso auxilio» ${ }^{26}$.

Sugiere que se replantee la posibilidad de que las mujeres tuvieran que pagar, porque «no parece muy seguro este medio, y podría serlo más el de lisonjear su vanidad, porque el sexo vence fácilmente sus más radicales inclinaciones cuando espera conseguir aplauso». La solución que ofrece es establecer tres clases de asociadas: una primera clase para las bienhechoras, que podrían colaborar con ayudas a la Sociedad; la segunda sería para las meritorias, que se esperaba que colaboraran con los objetivos de la Matritense, y la tercera para las mujeres que hubieran obtenido premios y para las maestras.

Marín pedía en 1778 a la Sociedad que se definiera respecto a su memoria; sin embargo, desde esta última fecha hasta 1786 no se volvió a sacar más el tema, sin que se sepa muy bien la razón de ello, a pesar de que en 1785 accedió Jovellanos, uno de los máximos defensores de la admisión de las mujeres en la Sociedad, al puesto de director de la Matritense ${ }^{27}$, de la que ya había sido subdirector el año anterior.

En 1786 se reabrió de nuevo el debate con fuerza con la intervención de Cabarrús y Jovellanos ${ }^{28}$. Cabarrús se convirtió en el defensor de la idea de no admisión de las mujeres en la Sociedad, basándose en que «siempre y en todas partes se las ha excluido de las deliberaciones públicas». Después de hacer una serie de consideraciones sobre psicología femenina, viene a concluir diciendo que el lugar de la mujer austera y respetable está en su casa, en el hogar, «pero entiendo no contaremos con estas señoras, pero sí con las que siguiendo un todo opuesto se ven en todas partes, dan el tono, son el objeto de las conversaciones

26 Cfr. nuestro libro, op. cit., pág. 149.

27 Lucienne Domergue, en su obra Jovellanos à la Société Économique des Amis du Pais de Madrid, o. cit., pág. 243, señala que Jovellanos, al referirse a tal hecho después de decir «no sé ciertamente explicar este misterio», sugiere que «el juicio del público no vino en apoyo del de la Sociedad». También J. SArRaIlH, La España ilustrada de la segunda mitad del siglo XVIII, o. cit., pág. 252, viene a decir: «Los hechos no coronaron por tanto su esfuerzo, tan grande fue la resistencia, apoyada en pérfidas críticas venidas del exterior».

28 Estaba previsto que en la junta general de 18 de febrero de 1786 intervendrían Jovellanos y Cabarrús defendiendo sus respectivos puntos de vista; sin embargo, en la fecha citada sólo Cabarrús expuso su memoria por ausencia de Jovellanos. ARSEM, leg. 73, doc. 44. Consta en la documentación del archivo de la Matritense que el escritor asturiano leyó su memoria el 27 de marzo del mismo año. ARsem, Catálogo del Archivo de la Real Sociedad Económica Matritense, tomo III, ficha 1.681. «Memoria sobre la admisión de señoras», págs. 207-215, también leg. 73, doc. 41. 
y vendrán a perder en la Sociedad una parte de tiempo que les sobra [...]» ${ }^{29}$. Además, arguye Cabarrús, «será menester cercenar el número de socios y lo aumentamos: no podemos avenirnos entre hombres y llamamos a las mujeres» ${ }^{30}$.

Por su parte, Jovellanos presentaba una memoria, que analizaremos con más detalle en el apartado siguiente, en la que se mostraba partidario de la admisión de las mujeres y de su participación directa en las actividades de la Sociedad ${ }^{31}$, si bien desde una perspectiva paternalista, entendiendo que las mujeres entrarían en la Económica por su interés en instruirse y para participar de una manera organizada en la beneficencia pública, siendo el papel de los hombres inculcarles nociones de patriotismo y virtudes y talentos con su ejemplo. Por su parte, las damas que participarán en la Sociedad podrían servir de modelo al resto de las mujeres. Hay que tener en cuenta que Jovellanos suponía que las mujeres, por recato, nunca asistirían a las juntas y cooperarían a distancia en las tareas de la institución. Jovellanos finalizaba así su memoria: «Concluyo, pues, diciendo que las Señoras deben ser admitidas con las mismas formalidades y derechos que los demás individuos; que no debe formarse de ellas clase separada; que se debe recurrir a su consejo y auxilio en las materias propias de su sexo y del celo, talento y facultades de cada una $[\ldots]{ }^{32}$.

Pocos días después fue leída la memoria de Josefa Amar y Borbón sobre el mismo problema ${ }^{33}$. Esta memoria, además de estar bien elaborada, es bastante valiente y feminista:

Por una parte los hombres buscan su aprobación, les rinden unos obsequios que nunca se hacen entre sí. No les permiten el mando en lo público y se le concede absoluto en secreto. Las niegan la instrucción y después se quejan de que no la tienen. Digo las niegan, porque no hay un establecimiento público destinado para la instrucción de las mujeres...Por otra parte las atribuyen casi todos los daños que suceden.

La autora repasa históricamente todos los agravios sufridos por las mujeres y, respecto a la admisión en la Sociedad, dice:

29 ARSEM, leg. 73, doc. 44.

30 No debía de contar con mucho apoyo la línea tradicional expuesta por Cabarrús, porque a los pocos días entraba como miembro de la Sociedad Económica de Madrid María Isidra Quintina Guzmán y de la Serna.

ARSEM, leg. 73, doc. 9.

32 Jovellanos plantea una tesis de consenso, un tanto ambigua y reaccionaria, seguramente con la intención de vencer la resistencia de los socios más reacios a aceptar la entrada de mujeres en la Sociedad.

33 ARSEM, leg. 73, doc. 43. El documento lleva la fecha de 5 de junio de 1786 y fue leído en la Sociedad el 24 del mismo mes. Cfr., además, con el Catálogo del ARSEM, págs. 223 y ss. 
¿Son acaso algunas espías esparcidas por el Reyno que puedan dar noticia a los extraños de cuanto se trabaja por su bien?. ¿O son tan misteriosos e intrincados los asuntos que se tratan en las Sociedades Económicas que no pueden entenderlo sino los hombres?. Nada de esto hay, pero la importancia del asunto es igual, pues no se trata de menos que de igualar a las mujeres con los hombres [...].

Amar y Borbón, revisando los argumentos expuestos por Cabarrús y Jovellanos, viene a decir que nada daría más gloria a la Sociedad Económica que adaptarse a los nuevos tiempos que se estaban viviendo, asumiendo las nuevas funciones que la mujer debía desarrollar, colaborando al progreso de la comunidad como miembro de pleno derecho de la misma. Finaliza negando ser cierta la imposibilidad natural, de la que se acusaba a la mujer, para guardar la seriedad y el secreto de los asuntos públicos.

La memoria seguramente más lúcida e innovadora, presentada por Ignacio López de Ayala ${ }^{34}$, es la que cierra el debate en torno a la admisión de mujeres en la Matritense. Para Ayala el problema se centraba en

[...] saber si las mujeres españolas, esto es, si la mitad de España, han de permanecer inútiles como hasta aquí: o si por el contrario se le han de suministrar luces y conocimientos para que ayuden a los hombres y gobiernen con inteligencia sus caudales y familias; trátase de saber si se puede sacar de este sexo utilidad o si es un gremio réprobo que debe quedar abandonado a su capricho, a la inutilidad, ociosidad y desenvoltura; porque en sustancia esto se inquiere cuando se pregunta si han de tener parte en las Sociedades Económicas.

El autor se manifiesta feminista convencido; supone la igualdad del hombre y la mujer en todas las aptitudes y, a su parecer, «los hombres son los que han depravado al otro sexo. Celosos de una autoridad inhumana las reducen al ocio $[\ldots] »$.

Ayala refuta las tesis de los socios que se oponían a la entrada de las mujeres en la Sociedad y afirma: «Creo que por ningún otro medio se podrá vivificar más fácilmente la nación que [...] instruyendo a las mujeres, haciéndolas útiles en tantas artes mecánicas como pueden exactamente desempeñar ganará la agricultura y otros oficios, los brazos que ahora se emplean en aquélla [...]». Es decir, Ayala, además de mostrarse partidario de que las mujeres pudiesen entrar en la Sociedad, defiende las tesis de Campomanes y de la Quadra sobre la necesidad y utilidad del trabajo de la mujer en las diversas

34 ARSEM, leg. 72, doc. 4 . 
maniobras de la industria popular que el desarrollo económico demandaba en aquellos momentos.

En este apartado, de una manera resumida, hemos expuesto los términos del debate, que se extiende entre 1775 hasta 1786, centrado en torno a si la Matritense debía admitir personas del sexo femenino como socias con pleno derecho. La cuestión quedaría resuelta por una real orden de 27 de agosto de $1787^{35}$, que creaba la Junta de Damas de Honor y Mérito, adscrita a la Matritense, pero la discusión había dejado al descubierto las diferentes tendencias ideológicas existentes en la sociedad española del último tercio del siglo XVIII.

La memoria de Jovellanos acerca de la admisión y participación de las señoras en la Sociedad Económica Matritense

Dentro del contexto del debate que hemos expuesto es donde recobra un interés central la memoria leída por Jovellanos el 27 de marzo de 1786 en la Junta de la Sociedad, que analizamos a continuación con el suficiente detalle. El pensador gijonés había sido subdirector, primero, y después director de la entidad, pero en su época no tuvo ocasión de plantear la participación de mujeres en las actividades de la Matritense quizá porque, como él mismo dice en algún momento, la situación no estaba preparada para poder discutir y aprobar una cuestión de esa naturaleza.

Hay que tener en cuenta que Jovellanos llevaba suficientes años en Madrid como para conocer bien la realidad política del momento y tenía, además, importantes apoyos dentro de los grupos «ilustrados» cercanos al poder real. Estaba relacionado con personajes políticos del máximo rango, participaba en tertulias, era miembro de diversas academias y estaba muy bien considerado, a pesar de que también el grupo de sus enemigos se había engrosado bastante, como se demostraría en no mucho tiempo. Es decir, estaba en condiciones de influir entre los miembros de la Matritense porque su voz se consideraba autorizada y su opinión requerida y respetada.

Sin embargo, nos podemos preguntar, conociendo la trayectoria hasta el momento de Jovellanos, ¿̨cuál era previsible que fuera la posición de un ilustrado tan señalado como él ante la posible entrada de mujeres a la Real Sociedad Económica Matritense? En principio, hay que recordar que seguramente no haría nada distinto de lo que planteara Campomanes, con quien en ese momento

35 ARSEM, leg. 86, doc. 23. 
mantenía una estrecha relación de amistad y respeto, y era la máxima representación de la Ilustración oficial.

Por otra parte, en sus Diarios y en su correspondencia manifiesta siempre una valoración positiva de las mujeres pertenecientes a la aristocracia y a la alta burguesía que participaban en tertulias y en el mundo de la cultura con aprovechamiento y respeto a lo que consideraba el modelo femenino del momento. Es decir, no se pensaba en absoluto en otras mujeres que no fueran de ese tipo, y en ningún caso en las mujeres de clases populares, así como tampoco en las que siguieran los modelos del cortejo y otras prácticas que los ilustrados denunciaban como decadentes y corrompidas.

También hay que recordar que en su etapa sevillana definió con total rotundidad lo que pensaba de las mujeres desocupadas de la época, incluyendo a las monjas de clausura, con la conocida proposición que hace al arzobispo de Sevilla en una carta para que aquéllas combinaran las oraciones con el trabajo productivo $^{36}$. Porque, en contra de lo que se podría pensar desde una perspectiva actual, era previsible que el escritor asturiano, siguiendo la línea oficial ilustrada en este terreno, iba a dar su punto de vista sobre la entrada con condiciones de sólo algunas mujeres significativas por sus virtudes en la Matritense. Es decir, se imponía el principio de «la excepcionalidad frente a la regla».

Porque no hay que perder de vista que, como decíamos en la introducción, el debate que para la admisión de las mujeres se plantea en la Matritense en dos momentos culminantes del último tercio del siglo XVIII era un paso más dentro de la confrontación de orden político en un espacio que se consideraba uno de los cauces de la Ilustración en el que se trataban de redefinir los espacios masculinos y femeninos. De hecho, como mencionaremos más adelante, una vez conseguido el espacio, en este caso la creación de la Junta de Damas de Honor y Mérito, las socias no sólo se plantean utilizarlo adecuadamente, sino que no dudarán en intentar ampliarlo tanto en cantidad como en calidad.

En el comienzo de su memoria, Jovellanos quiere dejar establecido que la posible entrada de las mujeres en la Sociedad causó bastante revuelo e interés entre los socios cuando se planteó en la temprana fecha de 1775, especialmente porque la propuesta la hizo Pedro Rodríguez de Campomanes:

Pero después de haber oído los raciocinios con que sostuvo esta proposición aquel célebre individuo a cuya voz estuvieron fiados tanto tiempo los intereses

36 La última versión de dicha carta se encuentra en el tomo XIV de la edición de las Obras completas de Gaspar Melchor de Jovellanos, Oviedo, Instituto Feijoo de Estudios del Siglo XVIII - Ayuntamiento de Gijón - KRK Ediciones, 2010. Los tomos XIII y XIV contienen los escritos pedagógicos de Jovellanos con edición crítica, estudio introductorio y notas de Olegario Negrín Fajardo. 
del público; aquél que todavía los promueve con tanto ardor colocado a la frente de la Magistratura; después de haber observado la risueña perspectiva de bienes y ventajas que este padre y bienhechor de la Sociedad le presentó en la preciosa Memoria que tenemos a la vista, ¿quién se atreverá a sostener que aquellos anuncios de general condescendencia no eran dictados por el patriotismo y aprobados por la razón? ${ }^{37}$

Jovellanos manifiesta desconocer las razones por las que la Sociedad no llevó adelante la aceptación de las mujeres en su seno, porque en aquellos momentos él se encontraba desempeñando su profesión en Sevilla

[...] y en nuestras actas no hallo siquiera un rastro de luz que pueda ilustrarme acerca de ella. Pero si es lícito conjeturar en materia tan oscura, me inclinaré a creer que en aquel período el juicio del público no vino en apoyo de la Sociedad; que alguna conversación indiscreta, algún inconveniente no previsto suspendió la aprobación que estaba tan generosamente indicada, y en fin, que los que entonces gobernaban esperaron para realizar este designio aquella sazón oportuna que tiene señalada el destino al logro de las revoluciones políticas ${ }^{38}$.

En realidad, el asunto en cuestión se había puesto de nuevo sobre la mesa de otra manera, ya que no se discutía tanto la admisión de ciertas mujeres, que reunían las condiciones previstas por los ilustrados, como la participación de las mujeres en las juntas, después de la entrada

[...] de una dama nacida para ser excepción de su sexo y para honrarle, suena de repente en nuestra asamblea; todos los votos se reúnen en su favor; se la admite por aclamación en nuestra Sociedad. Abierto ya el paso se dispensa la misma distinción a otra dama tan conocida por su ilustre origen como por su elevado espíritu, y cuya generosidad había sabido granjearse anticipadamente la gratitud de este cuerpo $[\ldots]^{39}$.

37 ARSEM, leg. 73, documento 41. Cfr. nuestro libro Ilustración y educación, págs. 156 y ss. Aunque Jovellanos no menciona el nombre, nadie puede tener duda, y menos los que le escuchaban y leían en aquellos momentos, de que se refiere al conde de Campomanes. Un poco más tarde, al comienzo de la década de los noventa, las magníficas relaciones entre los dos asturianos se deteriorarían con la detención de Cabarrús al considerar Jovellanos que Campomanes no hizo lo necesario para ayudarle.

38 Ilustración y educación, pág. 157.

39 Ibidem. Lorenza de los Ríos y Loyo, marquesa de Fuerte Híjar, ingresó en la Matritense el 16 de agosto de 1788 formando el núcleo inicial de la Junta de Damas con otras mujeres de la nobleza como la condesa de Montijo y la de Benavente y duquesa de Osuna. Pero Jovellanos se refiere en su memoria a María Isidra Quintana Guzmán y Lacerda, hija de los condes de Oñate y graduada en la Universidad de Alcalá, nombrada por el claustro de dicha universidad catedrática honoraria de filosofía moderna y consiliaria perpetua en 
Jovellanos expone que «la admisión de las señoras se deberá hacer en la forma común» y no entiende cómo algunos pretenden que puedan ser admitidas en la Sociedad pero que no asistan libremente a las juntas; lo expresa con rotundidad: «Si admitimos a las señoras, no podemos negarles la plenitud de derechos que supone el título de socio, mas si tememos que el uso de estos derechos pueda sernos nocivos, no las admitamos. Cerrémosle de una vez y para siempre nuestras puertas». No obstante, Jovellanos pronto advierte que no cree que fueran reales los temores que algunos socios habían previsto acerca de la participación de las mujeres.

Para el escritor asturiano se estaba planteando un falso problema porque las mujeres dispuestas a entrar y que fueran admitidas serían pocas y para ello sería fundamental elegirlas «por el decoro, por la humanidad, por la beneficencia, por aquellas virtudes civiles y domésticas que hacen el honor de este sexo» y no por el nacimiento, la riqueza y la hermosura. ¡ «Cuánta gloria no nos traerán los pocos nombres que agreguemos a nuestra lista! ¡Y sobre todo, qué poco deberemos temer de su concurrencia!» .

Es decir, nuestro autor considera que la entrada y participación de las mujeres elegidas por los directivos de cada momento lo serían en función de una serie de virtudes fundamentales; esta selección impediría que pudieran incorporarse a la Matritense mujeres mundanas y frívolas de aquellas que temía Cabarrús que lo hicieran. Seguramente, para tranquilizar a los elementos más conservadores, Jovellanos pone en duda que vayan a estar interesadas a participar en las reuniones periódicas en pie de igualdad con los hombres. Pero, en la citada afirmación, se reitera que serían pocas las mujeres admitidas, y eso es fundamental porque está manifestando la excepcionalidad frente a la norma; para Jovellanos no se trataba de una admisión generalizada, sino selectiva y teniendo en cuenta un determinado perfil.

La función que parece asignarles Jovellanos a las futuras socias se puede considerar poco avanzada, demasiado convencional, especialmente si se tienen en cuenta los planteamientos que por aquellas fechas haría en su memoria Josefa Amar y Borbón y en la suya Ignacio López de Ayala. La ocurrencia de Jovellanos es pensar que las socias de la Matritense iban a participar como

la Facultad de Artes que fue propuesta por el duque de Osuna, entonces director de la Sociedad, en la junta general de 25 de febrero de 1786. La duquesa de Benavente, mujer del director, fue admitida en julio del mismo año. Se puede afirmar que estas tres importantes mujeres de la aristocracia, y el resto del núcleo inicial de la Junta de Damas, son representativas de una minoría ilustrada femenina muy preparada, que conocía idiomas, estaba al tanto de los avances científicos y de las nuevas producciones literarias y, lo que puede ser más importante, sintonizaba perfectamente con la política modernizadora ilustrada con la que colaboraron a través de sus actividades de beneficencia y apoyo a la educación femenina, con la intención manifiesta de que las mujeres se incorporaran al mundo productivo. 
meras comparsas de los hombres para animarlos con sus aplausos y halagarlos con sus alabanzas: «Hagamos, pues, que las damas conozcan el patriotismo; hagamos que aprecien a los que le profesan, y veréis multiplicarse infinitamente el número de patriotas».

Es verdad que, de forma complementaria, Jovellanos insistirá en que no se puede dejar abandonada la mitad de la población a la corrupción a la que, al parecer, estaba condenado el sexo femenino, y pedirá que aquellas mujeres ejemplares se incorporasen a la Sociedad Económica Matritense para que pudieran desarrollar y ejercitar su virtud y sus talentos, al tiempo que servirían de efecto llamada «a las que vengan a imitarlas». El panorama de la época tal como lo percibe el asturiano era el siguiente: «Poned por un instante la vista en aquella misma porción que suele ser objeto de nuestras declamaciones. Ved la tendencia general con que camina a la corrupción. Ved por todas partes abandonadas las obligaciones domésticas, menospreciado el decoro, olvidado el pudor, desenfrenado el lujo y canceradas enteramente las costumbres ${ }^{40}$.

Sin embargo, lo que manifiesta Jovellanos es que la discusión es vana, porque, en realidad, las mujeres no van a tener ningún interés en participar en las actividades de la Sociedad, como mucho participarían en algún momento concreto, como en la entrega de premios o algún acto benéfico. ¿̨Se trata de una estrategia del autor o es que realmente piensa que las socias no van a participar en las reuniones de la Matritense? Porque la cuestión está en que si realmente no iban a participar, ¿para qué debatir en torno a su admisión?

En realidad, Jovellanos está preparando su conclusión, y es que dirá sí a la admisión y a la participación de mujeres en la Matritense, pero desde su casa o, en cualquier caso, «las asociadas deberán concurrir solas y separadas a trabajar por la causa común». Todavía estaba lejos Jovellanos de entender la admisión pura y simple de las mujeres con los mismos derechos y deberes que los hombres, participando en las mismas actividades, si bien parece que, al menos, no tenía duda de su valía y de sus posibilidades de futuro. De hecho, sugiere que se le podría dar el título de protectorado de algunas de las escuelas, como así ocurriría en el futuro; sugiere que formen una organización separada con un reglamento propio, y de hecho pronto surgirá la Junta de Damas de Honor y Mérito.

Pero también hay que destacar por encima de todo la concepción tradicional jovellanista de las mujeres que, en realidad, era la dominante en la época: «Que se debe recurrir a su consejo y a su auxilio en las materias propias de su sexo y del celo, talento y facultades de cada una». Jovellanos planteaba así lo que era entonces la manera común de pensar de la época y que entre nosotros

$40 \quad$ Ibidem, pág. 159. 
siguió existiendo aún durante bastante tiempo, de manera predominante durante el franquismo. Claro que en las palabras del escritor asturiano se puede interpretar un sesgo marcadamente utilitarista y positivo al valorar a las mujeres en los ámbitos que controlaban mejor y pedir su participación en ellos.

Finalmente, se zanjaría el problema, como hemos señalado, por la real orden de 27 de agosto de $1787^{41}$ que permitía la creación de la Junta de Damas adscrita a la Matritense y fijaba sus objetivos y finalidades e, incluso, se sugería que las personas más adecuadas para formar parte de ella eran aquellas «que por sus circunstancias sean más acreedoras de esta honrosa distinción». Es importante señalar que se preveía que se reunieran en «juntas regulares separadas» y se proponían nueve señoras residentes en Madrid más otras cuatro que estaban ausentes, a las que hay que añadir a la condesa de Benavente y a María Isidra Quintana Guzmán y Lacerda, que habían sido nombradas previamente, como hemos mencionado. En total, pues, se constituía la nueva junta con quince mujeres, todas ellas pertenecientes a las clases sociales más altas y de contrastada cercanía a las tesis ilustradas, y se consideraba que se admitirían nuevas socias ${ }^{42}$.

Presidía la junta la condesa de Benavente y duquesa de Osuna y, como ya había sugerido Jovellanos, se nombró a dos socias como «curadoras» de cada Escuela Patriótica. De hecho, desde el primer momento se le encomienda el arreglo de las citadas escuelas que, después de un comienzo esperanzador, habían caído en una cierta crisis de producción y asistencia de alumnas. Se puede entender que, en realidad, llegó un momento en que los socios de la Matritense se plantearon incluso el cierre de las escuelas ante los escasos resultados que se estaban obteniendo, especialmente si se tienen en cuenta los objetivos que se habían planteado inicialmente, y vieron en la Junta una posible salida.

Destaca en los primeros años que las socias de la Junta de Damas pretenden alcanzar plena autonomía y la rica documentación de la Matritense prueba cómo se dirigieron diferentes escritos en ese sentido a la Junta General de la Sociedad. Los estatutos de $1794^{43}$ tampoco superaron los obstáculos, si bien reglamentaron con precisión la mayoría de los asuntos organizativos y de funcionamiento de las escuelas. Por el contrario, la aprobación de aquéllos llevó a la Junta de Damas a la confrontación directa con la Sociedad, porque entendían que eran «un cuerpo separado unido a la Sociedad para ayudarle en las tareas que le son más análogas, lo cual no dice dependencia ni superioridad porque

41 ARSEM, leg. 86, doc. 23.

42 De hecho, una socia que iba a tener bastante relevancia en el futuro fue la marquesa de Fuerte Híjar, que fue admitida como tal en la Junta de Damas el 16 de agosto de 1788.

43 Real orden de 10 de abril de 1794. ARSEM, leg. 130, doc. 5. 
no puede haberla entre dos cosas unidas» ${ }^{44}$. Tampoco se mostraban conformes las socias con que la elección de sus cargos directivos y la relación con otras instituciones estuvieran mediatizadas por la Sociedad. En la práctica, las socias funcionaban un órgano autónomo pero jurídicamente la Sociedad no se pronunció nunca en tal sentido de manera oficial y cuando los censores tenían que informar, siempre recordaban la dependencia de la Junta de Damas, pero se impondría la realidad y es que las socias se hicieron imprescindible para la continuación de las escuelas populares de la Matritense y, de hecho, su época fue la de mayor solidez de las mismas ${ }^{45}$.

\section{Conclusiones}

El debate en torno a la admisión de mujeres en la Real Sociedad Económica de Madrid, entre 1775 y 1786, se convirtió en una discusión más amplia en el tiempo que abarcó problemas relacionados con la sociedad, la cultura, la tradición, el modernismo y, en definitiva, con la tensión dialéctica de mentalidades enfrentadas, si bien todas ellas formando parte del sentir «ilustrado» reformador.

Se puede decir que se trató de un proceso de clarificación ideológica que resultó positivo, ganando una batalla más las mujeres como colectivo marginado en la relación social tradicional. Sin embargo, la razón más profunda del avance conseguido estaba en la necesidad de que las mujeres que aspiraban a ser socias de la Matritense se ocuparan del control y dirección de la enseñanza de las escuelas populares, a las que asistían únicamente niñas que eran instruidas por maestras. Es decir, en nuestra opinión influyó bastante en la decisión la incapacidad de los socios de sacar adelante las Escuelas Patrióticas y las otras escuelas populares, más que la cualificación y capacidad de las mujeres que aspiraban a ser consideradas socias en igualdad de derecho con los hombres.

44 ARSEM, leg. 9, doc. 36, folios 10 y 11.

45 En diversos trabajos nuestros nos hemos ocupado de la relación entre la Junta de Damas y la Real Sociedad en el ámbito educativo: «La reforma ilustrada de la educación popular al servicio del desarrollo económico en Campomanes», en D. Mateos Dorado (ed.): Campomanes, doscientos años después, págs. 529546; «Máquinas e instrumentos para la educación popular en las Escuelas Industriales de la Matritense», en XII Coloquio Nacional de Historia de la Educación, Burgos, Universidad de Burgos, 2003, págs. 219-229; «El proceso de alfabetización en las escuelas populares de la Real Sociedad Económica de Amigos del País de Madrid (1775-1808)», en 28th Session of the International Standing Conference for the History of Education, ISCHE28, Umea (Suecia), Abstract Book, 2006, pág. 100; «La educación popular de la Real Sociedad Económica Matritense: ¿formación profesional o trabajo artesanal», en Congreso Internacional Ilustración, Ilustraciones, Azkoitia, 2007. 
En última instancia, se trataba de poner en práctica las doctrinas ilustradas del progreso y la modernización del país, que se pueden resumir en una frase: la educación al servicio del desarrollo económico de España. En este ámbito, por razones pragmáticas e ideológicas, no se podía dejar al margen al colectivo de mujeres, que, además, al menos una minoría de ellas era consciente de su valía y de su poder. Un ejemplo de ello puede ser la existencia de tertulias auspiciadas por determinadas nobles admiradas y respetadas por todos los contertulios, entre los que destacaban los ilustrados más significativos del momento.

Es muy posible que la aparente conquista social que conseguían las mujeres, después del debate para su admisión en la Sociedad Económica Matritense, y la posterior creación de la Junta de Damas, no fuera tanto una victoria arrancada a los controladores sociales como una concesión interesada basada en los valores de la utilidad y la eficacia tan queridos por el progresismo ilustrado. En cualquier caso, el propio hecho de que se produjera un debate de las características del aquí comentado y los éxitos realmente conseguidos por una minoría de mujeres, que aspiraban a ser consideradas ilustradas, puede ser calificado de muy positivo teniendo en cuenta el contexto histórico en que se produjo.

Dentro de este contexto, la posición que mantiene Jovellanos está muy relacionada con su manera de actuar y de pensar, caracterizada por el equilibrio reformista; en cualquier caso, el pensamiento de Jovellanos representa perfectamente la síntesis ilustrada de la educación, en este caso femenina, al servicio del desarrollo económico nacional. Por eso, de la misma manera que hiciera Campomanes en sus proyectos reformistas, ya el asturiano plantea al arzobispo de Sevilla, con poco éxito, la posibilidad de que las monjas de clausura realicen actividades prácticas textiles que fueran compatibles con sus obligaciones religiosas.

Es verdad que el ideario ilustrado de Jovellanos es bastante limitado en lo que tiene que ver con el papel de la mujer y aún está lejos de considerarla en pie de igualdad con el hombre, aunque sí mantenga esa posición de principio. En la práctica, plantea que las mujeres sirvan como una manera de potenciar las actividades de los hombres en la Matritense, que se sentirían halagados con la presencia y los ánimos que les dieran las mujeres.

La realidad pronto se encargaría de ir más allá de los planteamientos jovellanistas y las mujeres que se incorporan a la Matritense aspiran a su autonomía y a la constitución de un grupo organizado, teóricamente dependiente de la Sociedad, pero con una capacidad de gestión amplia, especialmente en los ámbitos de la educación popular y la beneficencia. Las damas de la Sociedad se fueron haciendo indispensables con el tiempo y llegaron a ser mucho más que un adorno, como algunos de los socios pretendieron, para convertirse en 
un ejemplo para otros grupos de mujeres en distintas sociedades económicas, a pesar de la oposición de las fuerzas más reaccionarias, que pretendían que nada cambiase en la sociedad que habían heredado de sus mayores.

Dicho con otras palabras, el espacio que habían conquistado con el apoyo de los ilustrados masculinos más avanzados sería una plataforma importante con la que seguir afianzando la apertura de otros nuevos espacios con la intención de corregir la realidad de los géneros en la práctica y alcanzar progresivamente cotas de actividad en el ámbito político y público.

En todo este debate, Jovellanos se inclinaría por la posición oficial en la que la mujer debía desempeñar las funciones de administradora de su hogar y educadora de sus descendientes en el ámbito doméstico, mientras que las funciones públicas quedaban en manos de los hombres. A lo más que llegaba Jovellanos era a admitir y apoyar de buen grado que las mujeres colaboraran con los hombres en facetas que consideraba propias de su sexo, como eran las relativas a la beneficencia pública y a la educación de las mujeres populares, dentro del más puro utilitarismo ilustrado de poner la educación al servicio del desarrollo económico. Eso explica que en varias ocasiones el político asturiano recuerde, en la senda de Campomanes, la importancia de que las damas de las clases sociales más elevadas sirvan de ejemplo a las mujeres populares por su laboriosidad y su preocupación por el mundo productivo.

La memoria de Jovellanos es una de las más extensas de las defendidas en el debate, junto con las de Marín, Cabarrús y Josefa Amar y Borbón, la más extensa, y la de Ignacio López de Ayala, pero no es la más avanzada desde la perspectiva de pensamiento acerca del género y de sus funciones. La postura más claramente feminista, en el sentido de defensa de la entrada y participación de las mujeres en las actividades de la Económica de Madrid, es la de Amar y Borbón, y enseguida viene la de López de Ayala, que defiende su incorporación en pie de igualdad en las tareas de la Sociedad, sin abandonar sus tareas domésticas. Por su parte, las palabras de Jovellanos plantean la entrada de algunas mujeres seleccionadas en la Matritense, pero no con los mismos derechos que los hombres ni su participación común en los debates, sino en una organización distinta en la que participaran ellas solas.

Finalmente, como hemos visto, la posición jovellanista, que en realidad era la postura oficial ilustrada, acabaría imponiéndose, y algunas mujeres de las clases sociales privilegiadas españolas entrarían en la Sociedad en grupo aparte y únicamente con unas funciones concretas determinadas por sus estatutos. Pero el paso adelante ya estaba dado y a él había contribuido Jovellanos a su manera, con su discreción, equilibrio y tacto político, y, en definitiva, con sus dependencias y carencias propias de la época que le había tocado vivir. 